\title{
Risk of mortality associated with respiratory syncytial virus and influenza infection in adults
}

\author{
Yong Shik Kwon ${ }^{1 \dagger}$, Sun Hyo Park ${ }^{1 \dagger}$, Mi-Ae Kim', Hyun Jung Kim', Jae Seok Park', Mi Young Lee²,
} Choong Won Lee ${ }^{3}$, Sonila Dauti ${ }^{1,4}$ and Won-II Choi ${ }^{1,5^{*}}$ (D)

\begin{abstract}
Background: Respiratory syncytial virus (RSV) infection constitutes a substantial disease burden in the general population. However, the risk of death for RSV infection has been rarely evaluated with confounders or comorbidities adjusted. We aimed to evaluate whether RSV infection is associated with higher mortality than seasonal influenza after adjusting for confounders and comorbidities and the effect of oseltamivir on the mortality in patients with influenza infection.
\end{abstract}

Methods: A retrospective cohort study was conducted on adult ( $\geq 18$ years) patients admitted to the emergency department and ward of a university teaching hospital for suspected viral infection during 2013-2015 ( $N=3743$ ). RSV infection was diagnosed by multiplex PCR $(N=87)$. Adults hospitalized for seasonal influenza during the study period were enrolled as a comparison group $(n=312)$. The main outcome was 20 -day all-cause mortality.We used Cox proportional hazard regression analyses to calculate the relative risk of death.

Results: Adult patients were less likely to be diagnosed with RSV than with influenza (2.3 vs 8.3\%, respectively), were older and more likely to be diagnosed with pneumonia, chronic obstructive pulmonary disease, hypoxemia, and bacterial co-infection. In patients with RSV infection, the 20-day all-cause mortality was higher than that for influenza, (18.4 vs 6.7\%, respectively). RSV infection showed significantly higher risk of death compared to the seasonal influenza group, with hazard ratio, 2.32 (95\% Cl, 1.17-4.58). Oseltamivir had no significant effect on mortality in patients with influenza.

Conclusions: RSV infection was significantly associated with a higher risk of death than seasonal influenza, adjusted for potential confounders and comorbidities.

Keywords: Respiratory syncytial viruses, Influenza, human, Mortality

\section{Background}

Respiratory syncytial virus (RSV) is a significant cause of lower respiratory tract infections in infants, and usually requires hospitalization, with the occurrence of death in extreme cases $[1,2]$.

During the past decades, many studies have clearly demonstrated RSV as a serious pathogen in certain adult

\footnotetext{
* Correspondence: wichoi@dsmc.or.kr

${ }^{\dagger}$ Equal contributors

'Department of Internal Medicine, Keimyung University Dongsan Hospital, Daegu, Republic of Korea

${ }^{5}$ Department of Internal Medicine, Keimyung University School of Medicine 194 Dongsan-Dong, Jung-Gu, Daegu 700-712, Korea

Full list of author information is available at the end of the article
}

populations including long-term care facilities [3-6] and immunocompromised host [7-10]. Although RSV infection in adults is often mild, the effects of RSV infection can be substantial in both healthy adults and hospitalized patients [11]. RSV infection can cause significant morbidity in hospitalized patients, with mortality rates up to $12 \%$ [12]. A recent study showed that hospitalized community-acquired pneumonia related with viral pathogens, influenza, and RSV comprised of $21 \%$ and $11 \%$ among all viral pathogens, respectively [13].

A retrospective cohort study showed that RSV infection, in combination with bacterial co-infection was associated with increased risk of mortality [14]. RSV 
infections may contribute to $5 \%$ to $10 \%$ of cases of chronic obstructive pulmonary disease (COPD) exacerbations [15], and 7\% of asthma admissions [11] in adults. Virus infections including RSV may explain seasonal mortality in the elderly [16].

In the 1990's, Influenza had attributable mortality more than 4 times higher than RSV in the elderly in a population-based study [17]. However, in the 2000's attributable mortality of influenza was less than 2 times compared with those of RSV [18]. Attributable hospitalization due to RSV was almost two-thirds those of influenza [19]. RSV is an increasingly common cause of illness and high morbidity in adults. A better understanding of complications and outcomes of adults hospitalized with RSV compared to influenza infection would be useful to identify high-risk adults. Furthermore, oseltamivir has been commonly prescribed in influenza infected patients since 2009. However, the efficacies of oseltamivir treatment are contradictory [20-25].

We investigated the 20-day all-cause mortality rate for hospital admitted patients with laboratory confirmed RSV compared to influenza. We also investigated the effect of oseltamivir on the mortality of patients with influenza infection.

\section{Methods}

\section{Study population}

A retrospective cohort study of hospitalized adults with RSV infection was conducted. All patients aged $\geq 18$ years admitted between January 2013 and December 2015, with suspected respiratory viral infections $(N=3743)$, were studied. If physicians suspected respiratory viral illness, then virus multiplex PCR was performed. We excluded 2980 subjects who had no identifiable viral infections, and 364 patients with viral infections other than influenza A/B or RSV infection (Fig. 1). RSV patients $(n=87)$ were compared with patients diagnosed with seasonal influenza $(n=312)$ during the same period (2013-2015).One patient had a mixed infection of influenza and RSV. Among RSV-infected patients, one patient had a mixed infection with bocavirus. Among influenza-infected patients, 5 patients had mixed infection with bocavirus, and 3 patients with coronavirus. All the patients with mixed infections were included in this study except the one patient who had a mixed infection of influenza and RSV.

The current study was approved by the institutional review board at Dongsan Hospital, Keimyung University School of Medicine. The need for written informed consent was waived. This study was conducted in compliance with the Declaration of Helsinki.

\section{Definitions}

An upper respiratory infection was defined as the presence of one or more of the following respiratory symptoms: cough, sputum production, rhinorrhea, sore throat, or dyspnea. Pneumonia was defined as the presence of a new or progressive infiltrate found using chest radiography, in addition to two or more of the following: fever, sputum production, rhinorrhea, sore throat, dyspnea, or a diagnosis of pneumonia by the attending physician. The outcome was designated as all-cause mortality up to 20 days after hospital admission.

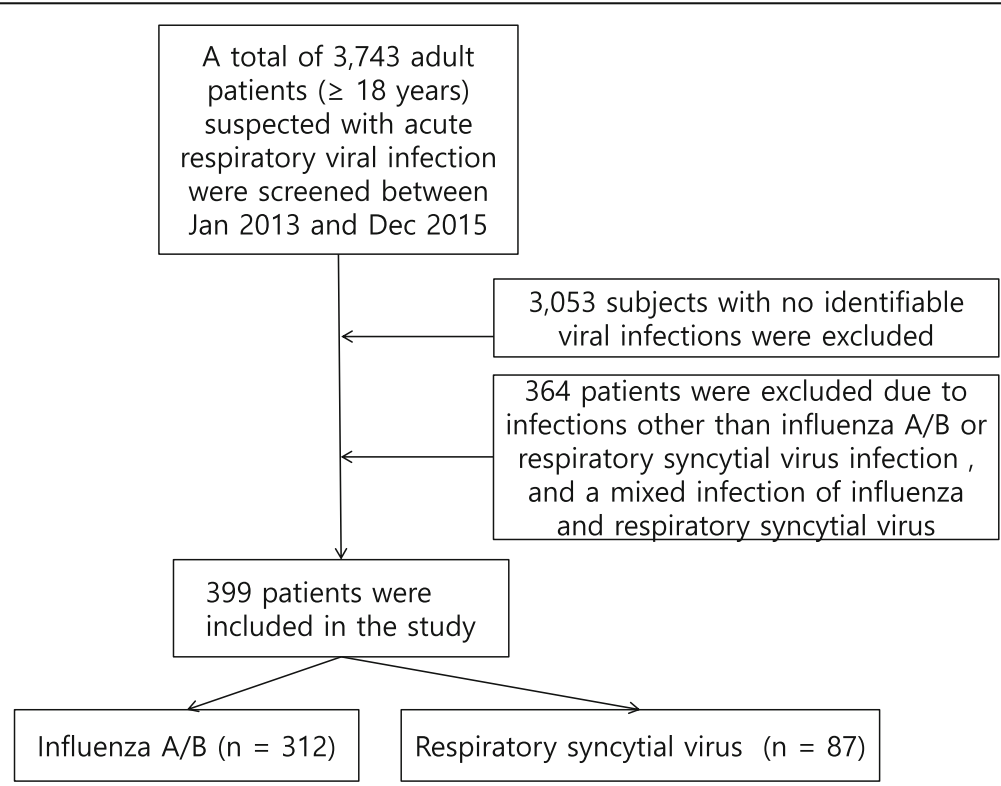

Fig. 1 Flow chart of patients suffering from respiratory virus infection 


\section{Specimens}

During the study period, nasopharyngeal specimens were obtained using flocked swabs and stored and transported using the universal transport medium (COPAN, Brescia, Italy). Nasopharyngeal specimens were submitted for respiratory virus detection. Nucleic acids were extracted from $300 \mu \mathrm{L}$ specimens using a Viral Gene- $\operatorname{spin}^{\mathrm{TM}}$ Viral DNA/ RNA Extraction Kit (iNtRON Biotechnology, Seongnam, Korea). cDNA was synthesized from each of the extracted RNA samples with cDNA Synthesis Premix (Seegene, Seoul, Korea) and a GeneAmp PCR System 9700 thermal cycler (Applied Biomaterials, Foster City, CA, USA).

\section{Respiratory virus testing}

Respiratory virus (RV) 16 testing was performed to detect the following viruses: adenovirus, influenza viruses $\mathrm{A}$ and $\mathrm{B}, \mathrm{RSV} \mathrm{A}, \mathrm{RSV} \mathrm{B}$, parainfluenza viruses 1 to 4, Rhinovirus $\mathrm{A} / \mathrm{B} / \mathrm{C}$, metapneumovirus, enterovirus, coronavirus 229E, coronavirus NL63, coronavirus OC43, and bocavirus. During the RV16 test, an internal control was added to each specimen to check the entire process from nucleic acid extraction to PCR, according to the manufacturer's instructions. An Anyplex II RV16 Detection Kit (Seegene, Seoul, Korea) was used to detect 14 types of RNA viruses and two types of DNA viruses, according to the manufacturer's instructions. Briefly, the assay was conducted in a final volume of $20 \mu \mathrm{L}$ containing $8 \mu \mathrm{L}$ of cDNA, $4 \mu \mathrm{L}$ of $5 \times \mathrm{RV}$ primer, $4 \mu \mathrm{L}$ of 8 -methoxypsoralen solution, and $4 \mu \mathrm{L}$ of $5 \times$ master mix with the CFX96 real-time PCR detection system (Bio-Rad Laboratories Inc., Hercules, CA, USA).

\section{Data collection}

This study was performed at Keimyung University Dongsan Hospital, a 867-bed, tertiary care teaching hospital in Daegu, Republic of Korea. If a patient had an episode of acute respiratory infection at an emergency department or outpatient clinic or within 2 days during admission, he or she underwent multiplex RT-PCR testing. Adult patients ( $\geq 18$ years of age) who underwent multiplex RT-PCR testing between January 2013 and December 2015 were identified by electronic medical records. We collected clinical data using the electronic medical record on general characteristics, co-morbidities, presenting symptoms, lower respiratory complications, requirement of supplemental oxygen therapy and/or ventilatory support, hospitalization duration, and allcause mortality. Chest radiography was performed on all patients admitted to the hospital, and radiographic interpretation was performed for all RSV and influenza cases by radiologists. Additional laboratory investigations were performed based on the results of a routine blood test. Sputum samples were collected for bacterial culture preparation at admission and during hospitalization. Blood cultures were also performed when indicated. Pneumonia severity index (PSI) consisted four parts, demographics including age and sex, co-morbidity, physical examination, and laboratory findings [26]. PSI score was collected every admitted patient. We contacted patients or their families by phone to identify survival and clinical information if the patients were not followed up regularly.

\section{Statistical analysis}

Baseline characteristics (including age, sex, residency in a long-term care facility, comorbidities, presenting symptoms, and complications) at date of admission for cases and control patients were summarized using descriptive statistics, such as proportion and means (standard deviation, SD). A Chi-squared test was applied for comparison between categorical variables, and two-tailed $t$-tests, for comparison between continuous variables. $P$ values $<0.05$ were considered statistically significant.

Fifty-two patients had missing data on body temperature due to lack of measurement in the outpatient clinic. We imputed 52 missing values for body temperature, 10 for RSV group and 42 for influenza group, using a sequential regression approach [27], assuming that body temperature was missing at random conditioning on all covariates included in the analysis.

The univariate and multivariate Cox regression models were used to evaluate the risk of death from RSV infection compared to that of seasonal influenza. The pneumonia severity index (PSI) score and resident of long-term care facilities were excluded from the final model due to multicollinearity with age. The multicollinearity between adjusting variables was checked by the variance inflation factor (VIF) and the tolerance statistic [28]. The largest VIF was 2.05 for PSI score and average VIF was 1.28. The smallest tolerance was 0.48 for PSI score. However, more detailed collinearity diagnostics indicated collinearity between age and PSI score. And when age and resident of long-term care facilities were entered simultaneously into the model, the hazard ratio for age changed its polarity. We analyzed survival curves for case and control subjects by the Kaplan-Meier method and compared them using the log-rank test. We assessed the assumption of proportional hazards with graphical and goodness-of-fit (GOF) approaches [29]. We considered ties when using Cox proportional hazards with the Breslow method [29]. Adjustments were made for sex, age, chronic obstructive pulmonary disease, body temperature $>37.5{ }^{\circ} \mathrm{C}$, pneumonia, hypoxemia and bacterial superinfection. Selection of covariates for the model building was based on clinical relevance and 
availability. The candidate variables for adjusting were sex, age, resident of long-term care facilities, COPD, high body temperature, pneumonia, bacterial superinfection, hypoxemia, and PSI score. All statistical analyses were performed using IBM SPSS V.21.0 (SPSS Version 23 for Microsoft Windows, IBM, Armonk, NY).

\section{Results}

\section{Clinical characteristics}

RSV seasonal peaks occurred during January in 2013, December in 2014, and January in 2015 (Fig. 2). The influenza season was defined as period between January and April, and was determined based on the weekly surveillance reports for influenza and other respiratory viruses prepared by the Korea Centers for Disease Control and Prevention.

RSV infection was diagnosed in 87 adult patients (54 A and $33 \mathrm{~B}$ ), and influenza infection, in 312 adult patients (244 A and $68 \mathrm{~B}$ ), during the 3-year study period. The percentage test positivity rates during this period were $2.3 \%$ and $8.3 \%$ for RSV infection and influenza, respectively among all patients tested with respiratory viruses multiplex PCR.

The average age of RSV-infected patients was older than that of influenza patients (70 and 62 years, respectively) (Table 1 ). RSV patients were more likely to be residents of a long-term care facility or to have COPD, pneumonia, or respiratory bacterial superinfection. Hypoxemia was more frequent and body temperature $>$ $37.5{ }^{\circ} \mathrm{C}$ was less common in RSV patients than in influenza patients (Table 1). Oseltamivir was prescribed for 248 influenza patients (79.4\%). Mechanical ventilation was used for 3 patients (3.4\%) with RSV infection, and

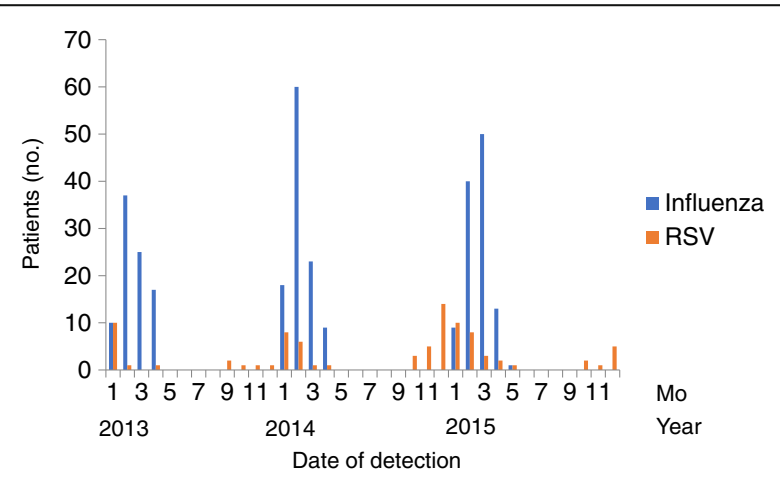

Fig. 2 Time of hospital admission of 87 adult patients with virologically confirmed respiratory syncytial virus (RSV) infection, and 312 adult patients with influenza infection, Daegu, Korea, 2013-2015. RSV seasonal peaks occurred during January in 2013, December in 2014, and January in 2015; the percentage test positivity rates during these periods were $11.4 \%$ and $40.8 \%$ for RSV and influenza, respectively among virus identified patients. Abbreviation: RSV, respiratory syncytial virus for 7 patients $(2.2 \%)$ with influenza. Mean PSI score was 21 points higher in RSV infection (107.5) than influenza (86.5).

\section{Outcomes}

All-cause 20-day mortality rates were higher in RSV patients than in influenza patients (18.4 and $6.7 \%$, respectively) (Fig. 3).

After adjusting for potential confounders and comorbidities, the hazard ratio (HR) $(2.32$; 95\% confidence interval [CI], 1.17-4.58) of 20-day all-cause mortality was significantly higher for RSV than influenza (Table 2).

\section{Effects of Oseltamivir in patients with influenza infection}

Eighty percent of influenza virus infected patients were treated with oseltamivir $(n=247)$, while the other $20 \%$ of these patients were not prescribed oseltamivir $(n=65)$. They were less likely to be treated with oseltamivir if diabetic, otherwise similar groups (Table 3). Oseltamivirtreated patients had no significant difference in mortality than the patients not treated with oseltamivir did; the 20-day all-cause mortality rates were $6.4 \%$ and $7.6 \%$, respectively ( $P=0.72$, Fig. 4$)$.

\section{Discussion}

This study showed that all-cause mortality within 20 days after hospital admission was higher in patients with RSV infection (18.4\%) than in those with influenza (6.7\%) and adjusted hazard ratio (RSV vs. influenza) was 2.32 (95\% CI, 1.17-4.58). However, oseltamivir had no significant effect on mortality in patients with influenza.

Previous epidemiologic study and retrospective cohort suggested the mortality rates related to RSV infection in the elderly was estimated $2-17 \%$ [12, 30-33]. The varying mortality rates related with RSV infection might be explained by high viral load and severity of infection $[32,33]$. In this study, the high PSI score in RSV infection might represent the severity of infection, which may partly explain the higher mortality from RSV infection in the current study than previously reported.

RSV infection is a significant cause of death in infants less than 12 months of age $[34,35]$. The serious problem of RSV was underestimated in elderly individuals until the 1970s [36]. Epidemiologic studies revealed that the RSV infection, like influenza infection, is also a significant cause of death or morbidity in elderly individuals $[17,37-40]$. However, the risk of mortality with RSV infection in the presence of comorbidities or confounders has not been explored well. In the present study showed RSV infection was an independent risk factor for mortality adjusting variables. 
Table 1 Baseline characteristics, morbidities, complications, outcomes of respiratory syncytial virus (RSV) and influenza infection cases, 2013-2015

\begin{tabular}{|c|c|c|c|}
\hline Variables & Influenza $\mathrm{A}$ or $\mathrm{B}(\mathrm{N}=312)$ & RSV $(N=87)$ & $P$ value \\
\hline Male, $n(\%)$ & $153(49.0)$ & $47(54.0)$ & 0.41 \\
\hline Age (years) mean (SD) & $62.6(17.1)$ & $70.0(12.2)$ & $<0.01$ \\
\hline Resident of long-term care facilities, $n(\%)$ & $6(1.9)$ & $9(10.3)$ & $<0.01$ \\
\hline Malignancy, n (\%) & $32(10.3)$ & $12(13.8)$ & 0.35 \\
\hline Congestive heart failure, $n(\%)$ & $23(7.4)$ & $8(9.2)$ & 0.57 \\
\hline Cerebrovascular accident, $n(\%)$ & $39(12.5)$ & $11(12.6)$ & 0.97 \\
\hline Chronic kidney disease, $n$ (\%) & $38(12.2)$ & $16(18.4)$ & 0.13 \\
\hline Diabetes, $n(\%)$ & $80(25.6)$ & $24(27.6)$ & 0.71 \\
\hline Liver disease, $n(\%)$ & $25(8.0)$ & $7(8.0)$ & 0.99 \\
\hline Chronic obstructive pulmonary disease, $n(\%)$ & $15(4.8)$ & $11(12.6)$ & $<0.01$ \\
\hline Asthma, $n(\%)$ & $20(6.4)$ & $3(3.4)$ & 0.29 \\
\hline Body temperature $>37.5^{\circ} \mathrm{C}, n(\%)$ & $110(35.3)$ & $17(19.5)$ & $<0.01$ \\
\hline Pneumonia, $n(\%)$ & $78(25.0)$ & $34(39.1)$ & $<0.01$ \\
\hline Respiratory bacterial superinfection, $n(\%)$ & $32(10.3)$ & $16(18.4)$ & 0.05 \\
\hline Hypoxemia, $n(\%)$ & $93(29.8)$ & $38(43.7)$ & 0.01 \\
\hline Mechanical ventilation, $n(\%)$ & $7(2.2)$ & $3(3.4)$ & 0.52 \\
\hline PSI score, mean (SD) & $86.5(34.9)$ & $107.5(30.0)$ & $<0.01$ \\
\hline Twenty-day all-cause mortality (\%) & $21(6.7)$ & $16(18.4)$ & $<0.01$ \\
\hline Sixty-day all-cause mortality (\%) & $38(12.2)$ & $22(25.3)$ & $<0.01$ \\
\hline
\end{tabular}

PSI pneumonia severity index, SD standard deviation

PSI was calculated in all patients with or without pneumonia

The body temperature was imputed for 52 patients

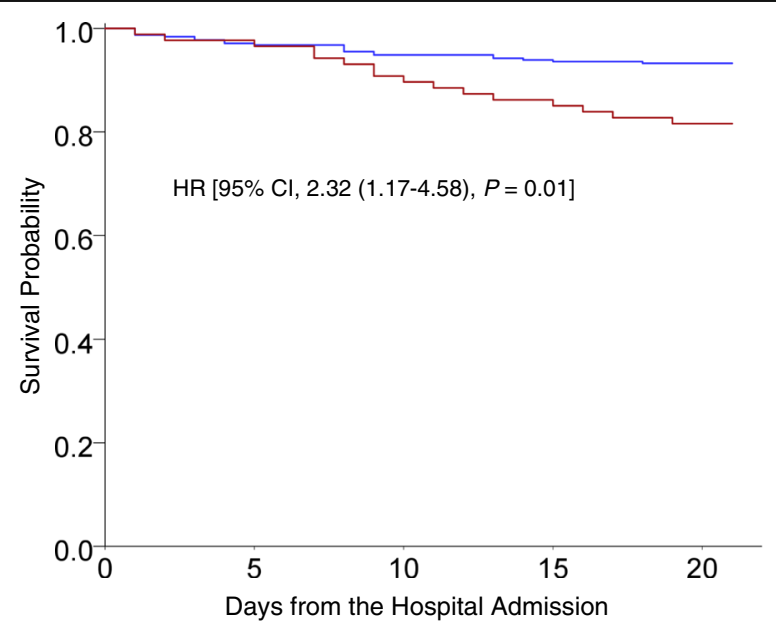

Fig. 3 Kaplan-Meier survival curves of 399 adults hospitalized with respiratory syncytial virus (RSV, red line) and influenza infection (blue line). Patients with RSV infection were shown to have lower survival rates. Between RSV and influenza infected patients, the crude 20-day all-cause mortality rate among RSV and influenza infected patients was $18.4 \%$ and $6.7 \%$, respectively
Although RSV data was based on both antigen detection and viral isolation methods [17], only antigen detection tests were used in the surveillance report since 2008 [41]. In addition to RSV, real-time PCR for detection of influenza viruses was implemented in the 2000's [42-44]. Since realtime PCR is more sensitive than antigen detection or virus isolation [45], there may be a difference in the description of the epidemiology between the pre- and post- PCR time periods. Thus, detecting methods may influence on virus epidemiology. Therefore, it would not be reasonable for direct comparison between previous epidemiologic studies and the present study.

Oseltamivir therapy showed effectiveness on reducing mortality in influenza infection [22-24]. However, there are still controversies about the effect of oseltamivir on the outcome of influenza-infected patients [21, 25]. In the present study, oseltamivir was prescribed in almost $80 \%$ of influenza infection cases. Although the difference in mortality rates failed to reach statistical significance, there was a trend towards influenza-infected patients treated with oseltamivir having a lower mortality rate than influenza-infected patients who were not treated with oseltamivir. We suspect that oseltamivir may partly contribute to the difference in mortality rates between RSV and influenza infection cases in the present study. 
Table 2 Variables associated with 20-day all-cause mortality in respiratory syncytial virus and influenza infection

\begin{tabular}{|c|c|c|c|c|}
\hline \multirow[b]{2}{*}{ Variables } & \multicolumn{2}{|c|}{ Univariate analysis } & \multicolumn{2}{|c|}{ Multivariate analysis } \\
\hline & $\mathrm{HR}(95 \% \mathrm{Cl})$ & $P$ value & $\mathrm{HR}(95 \% \mathrm{Cl})$ & $P$ value \\
\hline RSV infection & $2.83(1.47-5.43)$ & $<0.01$ & $2.32(1.17-4.58)$ & 0.01 \\
\hline Sex & $1.88(0.96-3.70)$ & 0.06 & $1.87(0.94-3.73)$ & 0.07 \\
\hline Age & $1.02(0.99-1.04)$ & 0.08 & $1.00(0.98-1.03)$ & 0.50 \\
\hline COPD & $4.31(1.97-9.43)$ & $<0.01$ & $2.97(1.28-6.90)$ & 0.01 \\
\hline Body temperature $(\mathrm{BT})>37.5^{\circ} \mathrm{C}$ & $0.79(0.38-1.63)$ & 0.52 & $1.08(0.50-2.35)$ & 0.82 \\
\hline Pneumonia & $2.00(1.04-3.84)$ & 0.03 & $1.72(0.84-3.51)$ & 0.13 \\
\hline Respiratory Bacterial superinfection & $0.89(0.31-2.52)$ & 0.83 & $0.56(0.19-1.65)$ & 0.29 \\
\hline Hypoxemia (< 60 mmHg) & $1.79(0.94-3.43)$ & 0.07 & $1.05(0.51-2.18)$ & 0.87 \\
\hline
\end{tabular}

The variables, resident of long-term care facilities and pneumonia severity index score, were not included due to collinearity $R S V$ respiratory syncytial virus, COPD chronic obstructive pulmonary disease, $H R$ hazard ratio, $\mathrm{Cl}$ confidence interval. Hazard ratios were calculated using a Cox Proportional hazards regression model

Our study showed that in adult patients, RSV infections can also cause pneumonia, resulting in respiratory failure in a higher proportion than seasonal influenza. RSV is the most significant cause of lower respiratory tract infections in infants and young children [46] and is known to be a significant cause of severe acute respiratory infections in elderly people [11, 47]. In our study, pneumonia was diagnosed in $39.1 \%$ patients. In 1984, similar results were observed in a nursing home for elderly during an outbreak of RSV infection [48].

In the present study, patients with RSV infection exhibited lower body temperature more frequently than patients with influenza did. In 2007, Walsh et al. [49] also reported that RSV infections were more commonly associated with lower temperature than influenza, and a greater proportion of RSV patients

Table 3 Baseline characteristics, morbidities, complications, outcomes of influenza infection cases treat with or without oseltamivir, 2013-2015

\begin{tabular}{|c|c|c|c|}
\hline Variables & $\begin{array}{l}\text { Influenza not treated with } \\
\text { Oseltamivir }(N=65)\end{array}$ & $\begin{array}{l}\text { Influenza treated with } \\
\text { Oseltamivir }(N=247)\end{array}$ & $P$ value \\
\hline Male, $n(\%)$ & $30(46.2)$ & $123(49.8)$ & 0.60 \\
\hline Age (years) mean (SD) & $61.2(18.3)$ & $63.0(16.7)$ & 0.44 \\
\hline Resident of long-term care facilities, $n(\%)$ & $1(1.5)$ & $5(2.0)$ & 0.80 \\
\hline Malignancy, n (\%) & $6(9.2)$ & $26(10.5)$ & 0.08 \\
\hline Congestive heart failure, $n(\%)$ & $8(12.3)$ & $15(6.1)$ & 0.08 \\
\hline Cerebrovascular accident, $n(\%)$ & $4(6.2)$ & $35(14.2)$ & 0.08 \\
\hline Chronic kidney disease, $n$ (\%) & $8(12.3)$ & $30(12.1)$ & 0.91 \\
\hline Diabetes, $n(\%)$ & $23(35.4)$ & $57(23.1)$ & 0.04 \\
\hline Liver disease, $n(\%)$ & $5(7.7)$ & $20(8.1)$ & 0.91 \\
\hline Chronic obstructive pulmonary disease, $n(\%)$ & $6(9.2)$ & $9(3.6)$ & 0.06 \\
\hline Asthma, $n(\%)$ & $6(9.2)$ & $14(5.7)$ & 0.29 \\
\hline Body temperature $>37.5^{\circ} \mathrm{C}, n(\%)$ & $17(26.2)$ & $93(37.7)$ & 0.08 \\
\hline Pneumonia, $n(\%)$ & $19(29.2)$ & $59(23.9)$ & 0.37 \\
\hline Respiratory bacterial superinfection, $n$ (\%) & $6(9.2)$ & $26(10.5)$ & 0.76 \\
\hline Hypoxemia, $n(\%)$ & $17(26.2)$ & $76(30.8)$ & 0.47 \\
\hline Mechanical ventilation, $n(\%)$ & $3(4.6)$ & $4(1.6)$ & 0.14 \\
\hline PSI score, mean (SD) & $85.0(36.6)$ & $86.9(34.5)$ & 0.70 \\
\hline Twenty-day all-cause mortality (\%) & $5(7.7)$ & $16(6.5)$ & 0.72 \\
\hline Sixty-day all-cause mortality (\%) & $12(18.5)$ & $26(10.5)$ & 0.09 \\
\hline
\end{tabular}

PSI pneumonia severity index, SD standard deviation 


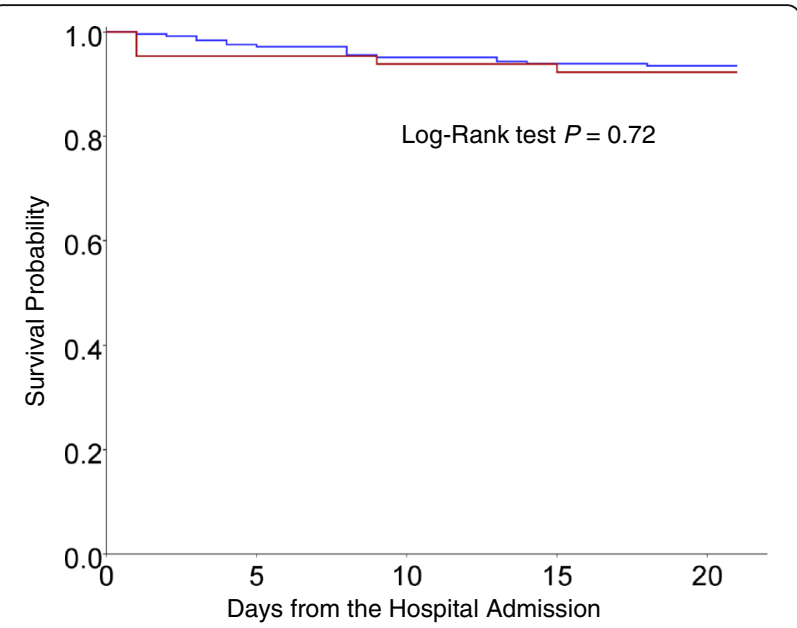

Fig. 4 Kaplan-Meier survival curves of 312 adults hospitalized for influenza virus infection, who did not undergo oseltamivir therapy (red line, $n=65$ ) and who did undergo oseltamivir therapy (blue line, $n=247)$. Twenty-day all-cause mortality rates among influenza patients treated with and without oseltamivir were $6.4 \%$ and $7.6 \%$, respectively $(P=0.72)$

developed pneumonia, than influenza patients. Similar results were previously observed in the study from Falsey et al. [39] in 1995 and Dowell et al. [47] in 1996.

The PSI was developed as a clinical prediction tool to guide doctors in deciding between inpatient or outpatient treatment of pneumonia patients [26]. Viral pneumonia may not be detected using simple chest radiography; however, ground glass opacity can be identified using chest computed tomography. Furthermore, RSV and influenza infection may have a significant impact on vital signs, as well as on laboratory findings. In the present study, the PSI score was significantly higher in RSV infection cases than in influenza cases by 21 points. We speculate that RSV infection may result in a more serious inflammatory response than influenza infection.

Although RSV infection accounted for only $2 \%$ of all adult respiratory viral infections in the present study, RSV infection should not be regarded as insignificant. If patients are suspected of having RSV infection, a prompt test for the respiratory virus should be the first step towards confirming diagnosis and treating patients. In addition to performing the test, the result should be made available quickly. Identification of the virus, as well as patients who are at a high risk of death, would help in prescribing antiviral therapies appropriately. Recent advances in the development of antiviral therapies for RSV are promising [50, 51], ensuring more options for treating RSV infections in the near future. If an effective vaccine for RSV becomes available, it would be prudent to target high prevalent groups, such as nursing home residents.

This study has several limitations. First, the absence of RSV or influenza in the nasopharynx does not exclude the presence of RSV or influenza in the lower respiratory tract. Thus, the results may underestimate RSV infection or influenza in lower respiratory tract infection. However, it was unlikely to affect the HR estimates. Second, we did not take into consideration vaccination against influenza, which may have reduced the impact of influenza illness. Third, data were retrospectively collected. Missing data and inadequate documentation including time to start medication may have resulted in biases in the study analysis. Fourth, there is a need for validation of the results with extended hospitals because of limited sources of the patients.

\section{Conclusions}

Our study showed that although RSV was detected less frequently in hospitalized adult patients, it was associated with a significantly higher risk of 20-day all-cause mortality than seasonal influenza.

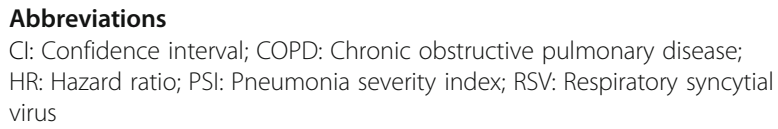

\section{Acknowledgements}

The biospecimens for this study were provided by the Keimyung Human Bio-Resource Bank (KHBB), a member of the National Biobank of Korea, which is supported by the Ministry of Health and Welfare. All samples derived from the National Biobank of Korea were obtained with informed consent under Institutional Review Board-approved protocols. We would like to thanks to Ms. Jin Hee Jeon for the preparing data sets.

\section{Funding}

This work was supported by a National Research Foundation of Korea (NRF) grant funded by the Korean Government (MSIP) (No. 2014R1A5A2010008).

\section{Availability of data and materials}

The datasets supporting the conclusion of this article is available. We presented the datasets in the additional supporting file. Data is available upon request. If someone wants to request the data should be contacted with Won-II Choi.

\section{Authors' contributions}

All authors have contributed either to the conception, original hypothesis, and design of the cohort. All authors have contributed to the writing of this article. YSK, SD, MAK, CWL, and SHP were responsible for drafted this manuscript. Data acquisition was performed by $\mathrm{W}-\mathrm{IC}$ and analysis was performed by JSP, SHP, MAK, HJK, MYL, CWL, and W-IC. All authors had full access to all the data in the study. All authors have read and approved the manuscript.

\section{Ethics approval and consent to participate}

The current study was approved by the institutional review board at Dongsan Hospital, Keimyung University School of Medicine. The need for written informed consent was waived. This study was conducted in compliance with the Declaration of Helsinki. 


\section{Competing interests}

The authors declare that they have no competing interests.

\section{Publisher's Note}

Springer Nature remains neutral with regard to jurisdictional claims in published maps and institutional affiliations.

\section{Author details}

'Department of Internal Medicine, Keimyung University Dongsan Hospital, Daegu, Republic of Korea. ${ }^{2}$ Department of Preventive Medicine, Keimyung University School of Medicine, Dongsan Hospital, Daegu, Republic of Korea. ${ }^{3}$ Department of Occupational \& Environmental Medicine, Sungso Hospital, Andong, Republic of Korea. ${ }^{4}$ Department of Allergology, Hospital Serive of Kavaje, Kavaje, Albania. ${ }^{5}$ Department of Internal Medicine, Keimyung University School of Medicine, 194 Dongsan-Dong, Jung-Gu, Daegu 700-712, Korea.

Received: 10 April 2017 Accepted: 10 December 2017

Published online: 20 December 2017

\section{References}

1. Boyce TG, Mellen BG, Mitchel EF Jr, Wright PF, Griffin MR. Rates of hospitalization for respiratory syncytial virus infection among children in medicaid. J Pediatr. 2000;137(6):865-70.

2. Leader $\mathrm{S}$, Kohlhase K. Recent trends in severe respiratory syncytial virus (RSV) among US infants, 1997 to 2000. J Pediatr. 2003;143(5 Suppl):S127-32.

3. Falsey AR, Walsh EE, Betts RF. Serologic evidence of respiratory syncytial virus infection in nursing home patients. J Infect Dis. 1990;162(2):568-9.

4. Falsey AR, Treanor JJ, Betts RF, Walsh EE. Viral respiratory infections in the institutionalized elderly: clinical and epidemiologic findings. J Am Geriatr Soc. 1992:40(2):115-9.

5. Garvie DG, Gray J. Outbreak of respiratory syncytial virus infection in the elderly. Br Med J. 1980;281(6250):1253-4.

6. Hornsleth A, Siggaard-Andersen J, Hjort L. Epidemiology of herpesvirus and respiratory virus infections. Part 1. Serologic findings. Geriatrics. 1975;30(8):61-8

7. Sica S, Leone G, Marra R, Falappa PG, Spanu T, Pagliari G, Mango G, Bizzi B. Respiratory syncytial virus infection in bone marrow transplantation: a case report (syncytial virus infection). Haematologica. 1990;75(2):184-6.

8. Sinnott JT, Cullison JP, Sweeney MS, Hammond M, Holt DA. Respiratory syncytial virus pneumonia in a cardiac transplant recipient. J Infect Dis. 1988;158(3):650-1.

9. Wendt $\mathrm{CH}$. Community respiratory viruses: organ transplant recipients. Am J Med. 1997:102(3A):31-6. discussion 42-33

10. Whimbey E, Englund JA, Couch RB. Community respiratory virus infections in immunocompromised patients with cancer. Am J Med. 1997;102(3A):108. discussion 25-16

11. Falsey AR, Hennessey PA, Formica MA, Cox C, Walsh EE. Respiratory syncytial virus infection in elderly and high-risk adults. N Engl J Med. 2005;352(17):1749-59.

12. Lee N, Lui GC, Wong KT, Li TC, Tse EC, Chan JY, Yu J, Wong SS, Choi KW Wong RY, et al. High morbidity and mortality in adults hospitalized for respiratory syncytial virus infections. Clin Infect Dis. 2013;57(8):1069-77.

13. Jain S, Self WH, Wunderink RG, Fakhran S, Balk R, Bramley AM, Reed C, Grijalva CG, Anderson EJ, Courtney DM, et al. Community-acquired pneumonia requiring hospitalization among U.S. adults. N Engl J Med. 2015; 373(5):415-27.

14. Miggins M, Hasan A, Hohmann S, Southwick F, Casella G, Schain D, Liu H, Bihorac A, Moldawer L, Efron P, et al. The potential influence of common viral infections diagnosed during hospitalization among critically ill patients in the United States. PLoS One. 2011:6(4):e18890.

15. Sethi S, Murphy TF. Infection in the pathogenesis and course of chronic obstructive pulmonary disease. N Engl J Med. 2008:359(22):2355-65.

16. van Asten $L$, van den Wijngaard $C$, van Pelt W, van de Kassteele J, Meijer A, van der Hoek W, Kretzschmar M, Koopmans M. Mortality attributable to 9 common infections: significant effect of influenza a, respiratory syncytial virus, influenza B, norovirus, and parainfluenza in elderly persons. J Infect Dis. 2012;206(5):628-39.

17. Thompson WW, Shay DK, Weintraub E, Brammer L, Cox N, Anderson L, Fukuda K. Mortality associated with influenza and respiratory syncytial virus in the United States. JAMA. 2003;289(2):179-86.
18. Matias G, Taylor R, Haguinet F, Schuck-Paim C, Lustig R, Shinde V. Estimates of mortality attributable to influenza and RSV in the United States during 1997-2009 by influenza type or subtype, age, cause of death, and risk status. Influenza Other Respir Viruses. 2014:8(5):507-15.

19. Matias G, Taylor R, Haguinet F, Schuck-Paim C, Lustig R, Shinde V. Estimates of hospitalization attributable to influenza and RSV in the US during 1997-2009, by age and risk status. BMC Public Health. 2017;17(1):271.

20. Hsu J, Santesso N, Mustafa R, Brozek J, Chen YL, Hopkins JP, Cheung A, Hovhannisyan G, Ivanova L, Flottorp SA, et al. Antivirals for treatment of influenza: a systematic review and meta-analysis of observational studies. Ann Intern Med. 2012;156(7):512-24.

21. Jefferson T, Jones M, Doshi P, Spencer EA, Onakpoya I, Heneghan CJ. Oseltamivir for influenza in adults and children: systematic review of clinical study reports and summary of regulatory comments. BMJ. 2014;348:g2545

22. McGeer A, Green KA, Plevneshi A, Shigayeva A, Siddiqi N, Raboud J, Low DE. Toronto invasive bacterial diseases $\mathrm{N}$ : antiviral therapy and outcomes of influenza requiring hospitalization in Ontario, Canada. Clin Infect Dis. 2007; 45(12):1568-75.

23. Muthuri SG, Venkatesan S, Myles PR, Leonardi-Bee J, Al Khuwaitir TS, Al Mamun A, Anovadiya AP, Azziz-Baumgartner E, Baez C, Bassetti M, et al. Effectiveness of neuraminidase inhibitors in reducing mortality in patients admitted to hospital with influenza a H1N1pdm09 virus infection: a metaanalysis of individual participant data. Lancet Respir Med. 2014;2(5):395-404.

24. Wang CB, Chiu ML, Lin PC, Liang WM, Chen CY, Chang YJ, Wu TN, Wang JH, Sung FC. Prompt Oseltamivir therapy reduces medical care and mortality for patients with influenza infection: an Asian population cohort study. Medicine. 2015;94(27):e1070.

25. Dobson J, Whitley RJ, Pocock S, Monto AS. Oseltamivir treatment for influenza in adults: a meta-analysis of randomised controlled trials. Lancet. 2015:385(9979):1729-37.

26. Fine MJ, Auble TE, Yealy DM, Hanusa BH, Weissfeld LA, Singer DE, Coley CM, Marrie TJ, Kapoor WN. A prediction rule to identify low-risk patients with community-acquired pneumonia. N Engl J Med. 1997;336(4):243-50.

27. Raghunathan TE, Lepkowski JM, Van Hoewyk J, Solenberger P. A multivariate technique for multiply imputing missing values using a sequence of regression models. Surv Methodol. 2001:27:85-95.

28. Field A. Discovering statistics using IBM SPSS statistics. 4th ed. Los Angeles: SAGE; 2013.

29. Kleinbaum DG, Klein M. Survival analysis: a self-learning text. New York: Springer; 2012.

30. Branche AR, Falsey AR. Respiratory syncytial virus infection in older adults: an under-recognized problem. Drugs Aging. 2015;32(4):261-9.

31. Volling C, Hassan K, Mazzulli T, Green K, Al-Den A, Hunter P, Mangat R, Ng J, McGeer A. Respiratory syncytial virus infection-associated hospitalization in adults: a retrospective cohort study. BMC Infect Dis. 2014;14:665.

32. Lee N, Chan MC, Lui GC, Li R, Wong RY, Yung IM, Cheung CS, Chan EC, Hui DS, Chan PK. High viral load and respiratory failure in adults hospitalized for respiratory Syncytial virus infections. J Infect Dis. 2015; 212(8):1237-40

33. Ong DS, Faber TE, Klein Klouwenberg PM, Cremer OL, Christiaan Boerma E, Sietses M, van Loon AM, Bonten MJ, Bont LJ. Respiratory syncytial virus in critically ill adult patients with community-acquired respiratory failure: a prospective observational study. Clin Microbiol Infect. 2014;20(8):0505-7.

34. Fleming DM, Pannell RS, Cross KW. Mortality in children from influenza and respiratory syncytial virus. J Epidemiol Community Health. 2005;59(7):586-90.

35. Shay DK, Holman RC, Roosevelt GE, Clarke MJ, Anderson L. Bronchiolitisassociated mortality and estimates of respiratory syncytial virus-associated deaths among US children, 1979-1997. J Infect Dis. 2001;183(1):16-22.

36. Hart RJ. An outbreak of respiratory syncytial virus infection in an old people's home. J Infect. 1984;8(3):259-61.

37. Fleming DM, Cross KW. Respiratory syncytial virus or influenza? Lancet. 1993. 342(8886-8887):1507-10

38. Jansen AG, Sanders EA, Hoes AW, van Loon AM, Hak E. Influenza- and respiratory syncytial virus-associated mortality and hospitalisations. Eur Respir J. 2007;30(6):1158-66.

39. Falsey AR, Cunningham CK, Barker WH, Kouides RW, Yuen JB, Menegus M, Weiner LB, Bonville CA, Betts RF. Respiratory syncytial virus and influenza a infections in the hospitalized elderly. J Infect Dis. 1995:172(2):389-94.

40. Nicholson KG. Impact of influenza and respiratory syncytial virus on mortality in England and Wales from January 1975 to December 1990. Epidemiol Infect. 1996;116(1):51-63 
41. Respiratory syncytial virus (RSV) surveillance. [https://www.cdc.gov/ surveillance/nrevss/rsv/index.html].

42. Boivin G, Cote S, Dery P, De Serres G, Bergeron MG. Multiplex real-time PCR assay for detection of influenza and human respiratory syncytial viruses. J Clin Microbiol. 2004:42(1):45-51.

43. Frisbie B, Tang YW, Griffin M, Poehling K, Wright PF, Holland K, Edwards KM. Surveillance of childhood influenza virus infection: what is the best diagnostic method to use for archival samples? J Clin Microbiol. 2004;42(3):1181-4.

44. Smith AB, Mock V, Melear R, Colarusso P, Willis DE. Rapid detection of influenza $a$ and $B$ viruses in clinical specimens by light cycler real time RTPCR. J Clin Virol. 2003;28(1):51-8.

45. Gueudin M, Vabret A, Petitjean J, Gouarin S, Brouard J, Freymuth F. Quantitation of respiratory syncytial virus RNA in nasal aspirates of children by real-time RT-PCR assay. J Virol Methods. 2003;109(1):39-45.

46. Glezen WP, Greenberg SB, Atmar RL, Piedra PA, Couch RB. Impact of respiratory virus infections on persons with chronic underlying conditions. JAMA. 2000;283(4):499-505.

47. Dowell SF, Anderson L, Gary HE Jr, Erdman DD, Plouffe JF, File TM Jr, Marston BJ, Breiman RF. Respiratory syncytial virus is an important cause of community-acquired lower respiratory infection among hospitalized adults. J Infect Dis. 1996;174(3):456-62.

48. Sorvillo FJ, Huie SF, Strassburg MA, Butsumyo A, Shandera WX, Fannin SL. An outbreak of respiratory syncytial virus pneumonia in a nursing home for the elderly. J Inf Secur. 1984;9(3):252-6.

49. Walsh EE, Peterson DR, Falsey AR. Is clinical recognition of respiratory syncytial virus infection in hospitalized elderly and high-risk adults possible? J Infect Dis. 2007;195(7):1046-51.

50. DeVincenzo JP, Whitley RJ, Mackman RL, Scaglioni-Weinlich C, Harrison L, Farrell E, McBride S, Lambkin-Williams R, Jordan R, Xin Y, et al. Oral GS-5806 activity in a respiratory syncytial virus challenge study. N Engl J Med. 2014; 371(8):711-22

51. Mejias A, Ramilo O. New options in the treatment of respiratory syncytial virus disease. J Infect. 2015;71(Suppl 1):S80-7.

\section{Submit your next manuscript to BioMed Central and we will help you at every step:}

- We accept pre-submission inquiries

- Our selector tool helps you to find the most relevant journal

- We provide round the clock customer support

- Convenient online submission

- Thorough peer review

- Inclusion in PubMed and all major indexing services

- Maximum visibility for your research

Submit your manuscript at www.biomedcentral.com/submit 